NBER WORKING PAPER SERIES

\title{
CHILDHOOD ENVIRONMENT AND GENDER GAPS IN ADULTHOOD
}

\author{
Raj Chetty \\ Nathaniel Hendren \\ Frina Lin \\ Jeremy Majerovitz \\ Benjamin Scuderi \\ Working Paper 21936 \\ http://www.nber.org/papers/w21936 \\ NATIONAL BUREAU OF ECONOMIC RESEARCH \\ 1050 Massachusetts Avenue \\ Cambridge, MA 02138 \\ January 2016
}

We thank David Autor, Alex Bell, David Grusky, Melissa Kearney, and Lawrence Katz for helpful comments. This research was funded by the National Science Foundation, the Lab for Economic Applications and Policy at Harvard, the Stanford Institute for Economic Policy Research, and Laura and John Arnold Foundation. All results based on tax data in this paper are constructed using statistics originally released in the SOI Working Paper "The Economic Impacts of Tax Expenditures: Evidence from Spatial Variation across the U.S.," approved under IRS contract TIRNO-12-P-00374. The views expressed herein are those of the authors and do not necessarily reflect the views of the National Bureau of Economic Research.

NBER working papers are circulated for discussion and comment purposes. They have not been peerreviewed or been subject to the review by the NBER Board of Directors that accompanies official NBER publications.

(C) 2016 by Raj Chetty, Nathaniel Hendren, Frina Lin, Jeremy Majerovitz, and Benjamin Scuderi. All rights reserved. Short sections of text, not to exceed two paragraphs, may be quoted without explicit permission provided that full credit, including (C) notice, is given to the source. 
Childhood Environment and Gender Gaps in Adulthood

Raj Chetty, Nathaniel Hendren, Frina Lin, Jeremy Majerovitz, and Benjamin Scuderi

NBER Working Paper No. 21936

January 2016

JEL No. J0,J16,J21

\begin{abstract}
$\underline{\text { ABSTRACT }}$
We show that differences in childhood environments play an important role in shaping gender gaps in adulthood by documenting three facts using population tax records for children born in the 1980s. First, gender gaps in employment rates, earnings, and college attendance vary substantially across the parental income distribution. Notably, the traditional gender gap in employment rates is reversed for children growing up in poor families: boys in families in the bottom quintile of the income distribution are less likely to work than girls. Second, these gender gaps vary substantially across counties and commuting zones in which children grow up. The degree of variation in outcomes across places is largest for boys growing up in poor, single-parent families. Third, the spatial variation in gender gaps is highly correlated with proxies for neighborhood disadvantage. Low-income boys who grow up in high-poverty, high-minority areas work significantly less than girls. These areas also have higher rates of crime, suggesting that boys growing up in concentrated poverty substitute from formal employment to crime. Together, these findings demonstrate that gender gaps in adulthood have roots in childhood, perhaps because childhood disadvantage is especially harmful for boys.
\end{abstract}

\author{
Raj Chetty \\ Department of Economics \\ Stanford University \\ 579 Serra Mall \\ Stanford, CA 94305 \\ and NBER \\ chetty@stanford.edu \\ Nathaniel Hendren \\ Harvard University \\ Department of Economics \\ Littauer Center Room 235 \\ Cambridge, MA 02138 \\ and NBER \\ nhendren@gmail.com \\ Frina Lin \\ Stanford University \\ Gunn-SIEPR Building 327 \\ Stanford, CA 94305 \\ frinalin@stanford.edu
}

\author{
Jeremy Majerovitz \\ Harvard University \\ Littauer Center 226 \\ Cambridge MA 02138 \\ jmajic@alumni.stanford.edu \\ Benjamin Scuderi \\ Harvard University \\ Littauer Center 226 \\ Cambridge MA 02138 \\ scuderi.b@gmail.com
}


A long literature has documented significant differences between men and women in earnings, employment rates, and other outcomes in adulthood (e.g., Altonji and Blank 1999, Blau and Kahn 2000, Goldin, Katz and Kuziemko 2006, Goldin 2014). The most prominent explanations for these gender differences focus on factors affecting the labor market, such as occupational preferences, fertility patterns, and discrimination. A separate, more recent literature has shown that the effects of family background and childhood environment on child development - as measured by outcomes such as test scores, disruptive behavior, and high school graduation rates - also differ significantly by gender (Alexander, Entwisle and Olson 2007, DiPrete and Jennings 2012, Bertrand and Pan 2013, Autor and Wasserman 2013, Autor et al. 2015). This paper connects these two literatures by examining the role of family characteristics and childhood environment in shaping gender gaps in adulthood.

We document three facts using population tax records for children born in the 1980s. First, gender gaps in employment rates, earnings, and college attendance vary substantially with parent income and marital status. Notably, the traditional gender gap in employment rates is reversed for children growing up in poor families: boys in families in the bottom quintile of the income distribution are less likely to work than girls, especially when raised by single parents. Second, these gender differences vary substantially across the areas (counties or commuting zones) in which children grow up. Most of this variation reflects the causal impact of childhood exposure to neighborhoods rather than selection effects (Chetty and Hendren 2015). The variation in outcomes across places is largest for boys growing up in poor, single-parent families. Third, the spatial variation in gender differences is highly correlated with proxies for neighborhood disadvantage. Low-income boys who grow up in high-poverty, high-minority areas work less than girls. These areas also have higher rates of crime, consistent with a model in which boys with lower latent earnings potential who grow up in environments of concentrated poverty switch from the formal labor market to crime or other illicit activities. We conclude that gender gaps in adulthood have roots in childhood, perhaps because poverty and exposure to disadvantaged neighborhoods during childhood are particularly harmful for boys. 


\section{Data}

We use the dataset constructed by Chetty et al. (2014) to study intergenerational mobility. This dataset is derived from a de-identified database of tax returns covering the U.S. population from 1996-2012. In our primary analysis, we focus on the "core sample" in Chetty et al. (2014), which consists of children born between 1980-82 who are U.S. citizens as of 2013. There are approximately 10 million children in this sample.

We identify each child's parents as the first tax filers (between 1996-2012) who claim the child as a dependent and were between the ages of 15 and 40 when the child was born. We define parent income as mean pre-tax family income averaged over the 5 years from 1996-2000. For tax filers, family income is defined as Adjusted Gross Income plus tax-exempt interest income and the nontaxable portion of Social Security and Disability benefits. For non-filers, family income is defined as the sum of wage earnings (reported on form W-2), unemployment benefits, and gross social security and disability benefits for both parents. In years where parents have no tax return and no information returns, family income is coded as zero. We exclude the $1.2 \%$ of children whose parents have zero family income between 1996-2000.

We examine three outcomes for children in adulthood: employment, earnings, and college attendance. Employment is defined as an indicator for having a W-2 form filed on one's behalf at age 30. As a robustness check, we consider alternative definitions of employment that account for non-wage earnings and self employment income using data from 1099 forms and Schedule $\mathrm{C}$ of 1040 forms. Earnings is defined as the sum of earnings reported on an individual's W-2 forms. College attendance is defined as an indicator for having one or more 1098-T forms filed by a college when a child is between the ages of 18 and 23. See Section III and Appendix A of Chetty et al. (2014) for further details on sample and variable definitions.

\section{Gender Gaps by Parent Income}

We begin by examining the cross-sectional association between children's employment rates and their parents' income. Figure 1 plots men's and women's employment rates at age 30 (as measured by having positive W-2 wage earnings) versus their parents' income percentile. We define parents' income percentiles by ranking the parents of children within each birth cohort based on 
family income. Employment rates rise rapidly with parent income for both boys and girls, but the association between parent income and employment rates is stronger for boys. In low-income families, there is a striking reversal of the traditional pattern that men have higher employment rates than women. Boys have lower employment rates than girls below the 26th percentile of the parent income distribution, and higher employment rates than girls above that point.

When we broaden the definition of employment to include non-employee compensation (Box 7, Form 1099) or self-employment income (Schedule C, Form 1040), we continue to find that the association between parent income and employment rates is stronger for boys than girls (Appendix Figure 1). We also find similar differences in gender gaps by parent income for recent cohorts in the Panel Study of Income Dynamics (Appendix Figure 2).

The reversal of the gender gap in low-income families occurs only among children who grow up with unmarried parents (Appendix Figure 3). Among children with married parents, men work more than women across the entire parental income distribution (although the gender gap narrows at lower parent income levels). Having unmarried parents is associated with lower employment rates for men relative to women throughout the parent income distribution, consistent with recent evidence that growing up in a single-parent household is particularly harmful for boys' outcomes during childhood (Bertrand and Pan 2013, Autor et al. 2015).

We also find a stronger association between parent income and earnings (measured in dollars or percentile ranks) as well as college attendance rates for boys than girls (Appendix Figure 4). Boys have higher income levels than girls throughout the parent income distribution because men have higher earnings than women conditional on working; however, the male advantage in earnings shrinks as parent income falls. For college attendance, the levels are reversed: girls have higher college attendance rates than boys in recent cohorts (Goldin, Katz and Kuziemko 2006). But once again, men raised in low-income families do especially poorly relative to women in terms of college attendance.

These cross-sectional patterns are consistent with the hypothesis that growing up in a disadvantaged childhood environment (i.e., a low-income family) is particularly detrimental for boys relative to girls. However, the cross-sectional correlations between parent income and gender differentials could also be driven by other factors. For example, lower income families are more likely to be black, and black men are more likely to be incarcerated than white men. Such racial 
differences could generate the cross-sectional patterns documented above even if gender gaps in adulthood are not influenced by the environment in which a child grows up. In the next section, we identify the effects of childhood environment more directly by examining local area variation in gender gaps. ${ }^{1}$

\section{Geographic Variation in Gender Gaps}

Children's outcomes in adulthood vary substantially based on where they grow up (Chetty et al. 2014). Chetty and Hendren (2015) show that most of this geographic variation is due to causal effects of childhood environment by analyzing families who move across areas. Building on these findings, we analyze how gender gaps in adulthood vary based on where children grow up.

We characterize spatial variation at two geographic levels: counties and commuting zones (CZs). CZs are aggregations of counties based on commuting patterns that provide a natural definition of local labor markets. We focus on the CZ-level results in the text; the qualitative patterns across counties are very similar. We first analyze the outcomes of children of "permanent residents" of each CZ - children whose parents never move in the years we observe them (1996-2012) - and then discuss the outcomes of children whose parents move between CZs. ${ }^{2}$

We begin with an example that illustrates the key geographic patterns. Figure 2 plots employment rates at age 30 by parent income quintile for men and women who grew up in the New York City and Charlotte CZs. ${ }^{3}$ Employment rates for women are fairly similar in New York and Charlotte throughout the parental income distribution. Boys with high-income parents also have similar employment rates in both CZs. In contrast, employment rates for men with low-income parents are much lower in Charlotte than in New York. For children with parents in the bottom quintile, boys who grow up in Charlotte are 12 percentage points (pp) less likely to be employed than girls; the comparable gap in New York is only $3 \mathrm{pp}$.

The large differences in gender gaps between New York and Charlotte for children who grow

\footnotetext{
${ }^{1}$ We cannot directly control for racial differences because we do not observe race in our data. However, race is just one of many potential unobservable factors that may confound the cross-sectional relationship between parent income and children's outcomes. This is why we turn to an approach that identifies the effects of childhood environment in a manner that is not confounded by any such unobservables.

${ }^{2}$ We assign children to CZs based on where their parents live (i.e., where they grew up) irrespective of where they live as adults when we measure their employment rates.

${ }^{3}$ In this figure as well as the rest of the paper, we define parent ranks in the national (rather than local) income distribution.
} 
up in low-income families are representative of the variation across CZs more generally. Figure 3 presents a CZ-level map of the male-female difference in employment rates for children with parents in the bottom quintile of the national distribution (see Appendix Figure 5 for analogous county-level maps). In the top decile of CZs (the lightest color on the map), boys who grow up in poor families have employment rates that are around $10 \mathrm{pp}$ higher than girls; in the bottom decile, women are $10 \mathrm{pp}$ more likely to work than men. Boys have particularly low employment rates relative to girls in the South and Midwestern cities such as Milwaukee and St. Louis; boys have very high employment rates relative to girls in the Mountain states and parts of Texas. ${ }^{4}$ The CZ-level data show that the aggregate gender gaps plotted in Figure 1 mask substantial variation across areas. In particular, the "reversal" of the gender gap in poor families is far from a universal pattern throughout the U.S.

To quantify the degree of spatial variation in employment rates across the parental income distribution more systematically, we calculate the population-weighted standard deviation (SD) of employment rates across CZs for males and females in each parent income quintile (Appendix Figure 6). ${ }^{5}$ For girls, the SD of employment rates is approximately $3 \mathrm{pp}$ at all levels of parent income. For boys, the SD of employment rates across CZs falls sharply from $5 \mathrm{pp}$ at the bottom of the parental income distribution to $2 \mathrm{pp}$ at the top. These results show that - consistent with the patterns observed in the New York vs. Charlotte comparison - the spatial variation in gender gaps is much larger for children growing up in poor families, and the majority of this variation comes from differences in employment rates of boys rather than girls. The variation in employment rates across CZs is particularly large for boys who grow up in single-parent households. For boys with parents in the bottom quintile of the household income distribution, the SD of employment rates across CZs is $5.5 \mathrm{pp}$ for those with unmarried parents and $3.4 \mathrm{pp}$ for those with married parents (Appendix Figure 7).

Importantly, Chetty and Hendren (2015) show that most of the variation in children's outcomes across CZs reflects the causal effects of childhood environment rather than differences in the types

\footnotetext{
${ }^{4}$ See Appendix Table 1 for a list of CZs with the largest and smallest gender differences in employment rates for children in low-income families among the 100 most populous CZs. The differences range from a 9.8 pp higher employment rate for men relative to women in Salt Lake City, UT to a 16 pp lower employment rate for women relative to men in Richmond, VA.

${ }^{5}$ When computing these standard deviations, we exclude the portion of the variation due to estimation error by subtracting the noise variance - estimated as the mean standard error squared - from the total variance of employment rates across $\mathrm{CZs}$.
} 
of people living in different areas (selection effects). They establish this result by showing that the outcomes of children who move to a given $\mathrm{CZ}$ converge in expectation to the outcomes of the permanent residents of that $\mathrm{CZ}$ in proportion to the number of years that the child grows up there. Moreover, Chetty and Hendren show that there is gender-specific convergence in outcomes in proportion to exposure time. When a family with a daughter and son moves to a place where boys do especially well, their son does better than their daughter in direct proportion to the number of years they spend growing up in the new area. Combining the findings of Chetty and Hendren (2015) with the results reported above, we conclude that gender gaps in adulthood are shaped by the neighborhoods in which children grow up. ${ }^{6}$

\section{Correlates of Gender Gaps}

What are the characteristics of areas that produce lower employment rates for low-income boys relative to girls in adulthood? In Figure 4, we correlate the male-female gender difference in employment rates for children with parents in the bottom quintile with various CZ-level characteristics: the fraction of black residents, measures of racial and income segregation, properties of the income distribution, the quality of the K-12 education system, proxies for social capital, measures of family structure, local tax rates, local college attendance and affordability, labor market characteristics, and migration flows. These variables are taken directly from Chetty et al. (2014, Figure VIII); see Appendix G of that paper for definitions and data sources for each variable.

Figure 4 plots point estimates of the magnitude of each univariate correlation (populationweighted) along with $95 \%$ confidence intervals, with standard errors clustered by state. The sign of the correlation is shown in parentheses next to each variable. Boys have lower employment rates than girls in areas with three characteristics: (1) a larger fraction of black residents, (2) greater residential segregation, as measured by Theil indices of racial and income segregation from Reardon (2011), and (3) less stable family structures, as measured by the fraction of single mothers and marriage rates. The association between all of these factors and gender gaps is stronger for children growing up with single parents rather than married parents (Appendix Table 2).

When the three strongest predictors of gender gaps are included together in a multivariable

\footnotetext{
${ }^{6}$ The fact that children's outcomes vary with the number of years they are exposed to a given area during childhood shows where a child grows up (rather than where he or she works as an adult) matters for gender gaps in adulthood.
} 
regression, income segregation and fraction black continue to predict the gender gap, while the fraction of single parents loses significance (Appendix Table 3, Panel A). Segregation and the fraction of black residents also predict the variation in gender gaps within states in a specification that includes state fixed effects. We also find similar results when we examine the gender gap in income ranks rather than employment rates (Appendix Table 3, Panel B). Finally, when we calculate the gender gap using Chetty and Hendren's (2015) estimates of the causal effect of growing up in each CZ based on families who move (Appendix Table 3, Panel C), we find that boys who grow up in more segregated areas do worse than girls (see Appendix A for further details on this analysis). This last finding shows that the correlation between segregation and gender gaps is largely driven by the causal effect of growing up in a more segregated area rather than differences in the types of families who live in such areas. ${ }^{7}$

In sum, there is robust evidence that boys who grow up in poor families in highly segregated neighborhoods - i.e., environments of concentrated poverty - have much lower employment rates than girls who grow up in the same environment. One potential explanation for this result is that growing up in poverty may induce low-ability boys to switch from formal employment to crime or other illicit activities, perhaps because of lower perceived returns to work (Kearney and Levine forthcoming). Since women have a much lower latent propensity to enter the criminal sector than men, this mechanism would generate differential impacts by gender. Consistent with this explanation, we find that CZs with higher levels of income segregation also have higher rates of crime $($ correlation $=0.27)$.

\section{Conclusion}

This paper has shown that childhood disadvantage - growing up in a poor family, a single-parent family, or a neighborhood with concentrated poverty - has particularly negative long-term effects on boys relative to girls. Understanding why boys are more vulnerable than girls - and how one can mitigate these effects - is a key area for future research.

More generally, our findings illustrate that gender gaps in adulthood can be better understood

\footnotetext{
${ }^{7}$ Using the causal estimates based on movers makes the correlation between the fraction black and the gender gap weaker. This suggests that the strong correlation between the fraction of black residents and male-female differences in employment rates for permanent residents in Figure 4 may be driven primarily by selection effects (e.g., black boys who grow up in poor families have lower employment rates independent of neighborhood effects).
} 
by starting one's analysis from childhood. For example, the secular decline in male labor force participation rates in the U.S. has been attributed to factors such as the aging of the population, changes in industrial structure, and globalization. Our findings suggest that part of the explanation may instead lie in the growth of residential segregation, income inequality, and the fraction of children raised in single-parent households - all factors associated with lower employment rates for boys relative to girls. To facilitate further analysis of this and other questions on gender differences, we have made statistics on employment rates and other outcomes by gender and parent income quintile publicly available by county and commuting zone on the Equality of Opportunity Project website. 


\section{References}

Alexander, K. L., D. R. Entwisle, and L. S. Olson. 2007. "Lasting Consequences of the Summer Learning Gap.” American Sociological Review, 72(2): 167-180.

Altonji, Joseph G., and Rebecca M. Blank. 1999. "Race and gender in the labor market." In Handbook of Labor Economics. Vol. 3, , ed. Orley Ashenfelter and David Card, 3143-3259. Elsevier Science.

Autor, David, and Melanie Wasserman. 2013. "Wayward Sons: The Emerging Gender Gap in Education and Labor Markets.” Technical Report, Third Way, Washington, DC.

Autor, David, David Figlio, Krzysztof Karbownik, Jeffrey Roth, and Melanie Wasserman. 2015. "Family Disadvantage and the Gender Gap in Behavioral and Educational Outcomes."

Bertrand, M., and J. Pan. 2013. "The trouble with boys: Social influences and the gender gap in disruptive behavior." American Economic Journal: Applied Economics, 5: 32-64.

Blau, Francine D., and Lawrence M. Kahn. 2000. “Gender Differences in Pay.” Journal of Economic Perspectives, 14(4): 75-100.

Chetty, Raj, and Nathan Hendren. 2015. "The Impacts of Neighborhoods on Intergenerational Mobility: Childhood Exposure Effects and County-Level Estimates."

Chetty, R., N. Hendren, P. Kline, and E. Saez. 2014. "Where is the land of Opportunity? The Geography of Intergenerational Mobility in the United States." The Quarterly Journal of Economics, 129(4): 1553-1623.

DiPrete, Thomas a., and Jennifer L. Jennings. 2012. "Social and behavioral skills and the gender gap in early educational achievement." Social Science Research, 41(1): 1-15.

Goldin, Claudia. 2014. "A Grand Gender Convergence: Its Last Chapter.” American Economic Review, 104(4): 1091-1119.

Goldin, Claudia, Lawrence F Katz, and Ilyana Kuziemko. 2006. "The Homecoming of American College Women: The Reversal of the College Gender Gap." Journal of Economic Perspectives, 20(4): 133-156.

Kearney, Melissa S, and Phillip B Levine. n.d.. "Does More Income Inequality Lead to Less Upward Mobility?" Brookings Papers on Economic Activity.

Reardon, Sean. 2011. “Measures of Income Segregation.” CEPA Working Papers. Stanford, CA: $\underline{\text { Stanford Center for Education Policy Analysis. }}$ 


\section{Appendix A. Panel Study of Income Dynamics: Sample and Variable Definitions}

Appendix Figure 2 examines the relationship between parent income and children's employment rates by gender using the Panel Study of Income Dynamics (PSID). ${ }^{8}$ To construct this sample, we use the family and individual files from the PSID, as well as a spine from the PSID which matches parents to children.

We define income as total labor income until 1993; after 1993, we define income as total labor income excluding farm and business income, which is the primary definition of labor income in the PSID after 1993. We compute the income of each parent as their average labor income from ages 30 to 50 (or whatever subset of those ages for which they are in the sample). We use a longer average in the PSID than we do in the tax data (where we average income over 5 years) to account for the greater degree of measurement error in the PSID, as discussed in Chetty et al. (2014). We define parent family income as the sum of the father's and mother's average income.

We define an indicator for the child's employment based on their response at age 30 to the employment status question. We consider a child employed if they answer that they are "working now" or "temporarily laid off" when asked about their employment status. A few children appear twice at age 30 due to the timing of the PSID survey; we assign these children a single observation where their employment is defined as the average of the two observed values of employment. Some children who are interviewed at age 30 are not asked the employment question (e.g., due to institutionalization); these children are coded as unemployed to match our definition in the tax data. In addition, employment in adulthood is not observed for many children due to attrition from the sample. We code these observations as missing and exclude them from our analysis.

\section{Appendix B. Correlates of Gender Gaps: Permanent Residents' Outcomes vs. Causal Effects}

This appendix discusses the analysis in Appendix Table 3, which correlates selected CZ characteristics with different estimates of gender gaps.

\footnotetext{
${ }^{8} \mathrm{We}$ are grateful to Alex Bell for suggesting and helping us implement the comparison to the PSID.
} 
Motivation. In Figure 4 of the paper, we present correlations of gender differences in employment rates for children who grew up in different CZs with a range of characteristics of those CZs. These correlations with gender differences could reflect either the causal effect of growing up in $\mathrm{CZ}$ with certain characteristics or sorting of different types of families to such CZs. For instance, families who live in high-poverty neighborhoods might have different characteristics that lead to worse outcomes for boys relative to girls, which would lead to the observed correlation even if growing up in a high-poverty $\mathrm{CZ}$ does not have differential causal effects by gender. To address this problem, one must correlate characteristics such as poverty rates with estimates of the causal effect of growing up in each $\mathrm{CZ}$ on gender gaps.

Estimates of Causal Effects. Chetty and Hendren (2015) estimate gender-specific causal effects of spending an additional year growing up in each CZ by analyzing families who move across CZs. Their estimates are identified from differences in the ages at which children move to different CZs. Intuitively, if children who move from New York to Boston do better as adults the earlier they move, one can infer that growing up in Boston has a positive causal effect relative to New York. Building on this logic, Chetty and Hendren (2015) estimate a fixed effects model that identifies the causal effect of spending an additional year of childhood in each $\mathrm{CZ}$ on earnings in adulthood, separately for boys and girls. We multiply these annual exposure effect estimates by 20 to obtain an estimate of the causal effect of growing up in each $\mathrm{CZ}$ from birth.

Note that Chetty and Hendren (2015) do not compute causal effects on employment rates for children who grow up low-income families. Instead, they estimate effects on individual income ranks at age 26 for children whose parents are at the 25 th percentile of the parental income distribution. Individual income is defined as the sum of individual W-2 wage earnings, UI benefits, SSDI payments, and half of household self-employment income (see Online Appendix A of Chetty et al. (2014) for details). We translate this income measure into percentile ranks (scaled from 0-100) by ranking children relative to other children in the same birth cohort.

Since estimates of causal effects for employment rates are not available, we first compare results for employment rates and individual income ranks in the sample of permanent residents 
(non-movers) and then turn to the causal effect estimates. In the interest of space, we focus on three of the strongest predictors of gender gaps in employment rates: segregation of poverty, the fraction of black residents in the $\mathrm{CZ}$, and the fraction of single parents.

Results for Employment Rates at Age 30. In Panel A of Appendix Table 3, we regress gender differences (male - female) in employment rates at age 30 for children with parents in the bottom income quintile on the three CZ-level characteristics. Each covariate is standardized to have mean 0 and standard deviation of 1 in the full sample, so the regression coefficients can be interpreted as the effect of a $1 \mathrm{SD}$ increase in the covariate on the male-female difference in employment rates (measured in percentage points). The sample used to estimate these regressions consists of children whose parents never moved across CZs, as in Figure 3.

Columns 1-3 report estimates from univariate regressions, replicating specifications reported in Appendix Table 2. Boys who grow up in areas with greater segregation, a higher fraction of African Americans, or more single parents have lower employment rates than girls who grew up in the same areas. Column 4 includes all three of these variables in a multivariable regression. Both segregation and the fraction black continue to have a significant relationship with the gender difference in employment; however, the coefficient on the fraction of single parents falls and is no longer significantly different from zero. Column 5 adds state fixed effects and shows that both segregation and the fraction black remain significant predictors of the gender gap in employment across CZs within states.

Results for Income Ranks at Age 26. Next, we show that the pattern of correlations is similar when measuring children's outcomes using their income rank at age 26, as in Chetty and Hendren (2015), instead of employment rates at age 30. Panel B of Appendix Table 3 replicates the specifications in Panel A, changing the dependent variable to the gender difference in mean individual income rank at age 26 for children with parents at the 25 th percentile of the national income distribution. These mean ranks are estimated as in Chetty et al. (2014) using linear regressions of children's percentile ranks on parent ranks.

Once again, we find that areas with greater segregation, a higher fraction of African Americans, 
and more single parents have better outcomes for women relative to men. For example, a one standard deviation increase in the segregation of poverty is associated with a 3 percentile reduction in men's expected rank relative to women who grow up in the same areas. In the multivariable regression in Column 4, both segregation and the fraction black have a significant relationship with the gender difference in individual income ranks. However, the coefficient on the fraction of single parents is positive but not statistically significantly different from zero, similar to the result for employment rates at age 30. Adding state fixed effects in Column 5 does not change these results. In short, the correlates of the gender gap in individual income ranks at age 26 are very similar to those observed for employment rates at age 30.

Results for Causal Effects on Income Ranks at Age 26. Finally, in Panel C, we turn to the correlates of the gender gap in causal effects estimated based on the outcomes of children whose families moved across CZs. We replicate the same specifications as in Panel B, changing the dependent variable to the gender difference in the causal exposure effect estimates reported in Chetty and Hendren (2015) for children with parents at the 25th percentile (multiplied by 20 to obtain the effect of 20 years of exposure).

Consistent with the pattern seen for the permanent residents in Panel B, we find that a one standard deviation increase in the segregation of poverty is associated with a 2.5 percentile reduction in men's expected rank relative to women who grow up in the same areas. The coefficient on segregation remains quite stable even when controlling for the fraction of black residents and single parents (Column 4) and including state fixed effects (Column 5). Hence, there is robust evidence that growing up in an area with greater segregation produces worse economic outcomes for men relative to women in low-income families.

In contrast, using the causal estimates of the gender gap yields smaller coefficients on the fraction black and fraction single parents relative to the specifications for permanent residents in Panel B. This suggests that some of the correlation between permanent residents' outcomes with the fraction black and single parents is driven by sorting (selection effects) rather than a correlation with the causal effect of childhood exposure to such areas. 
Figure 1. Children's Employment Rates at Age 30 by Gender and Parent Income Percentile

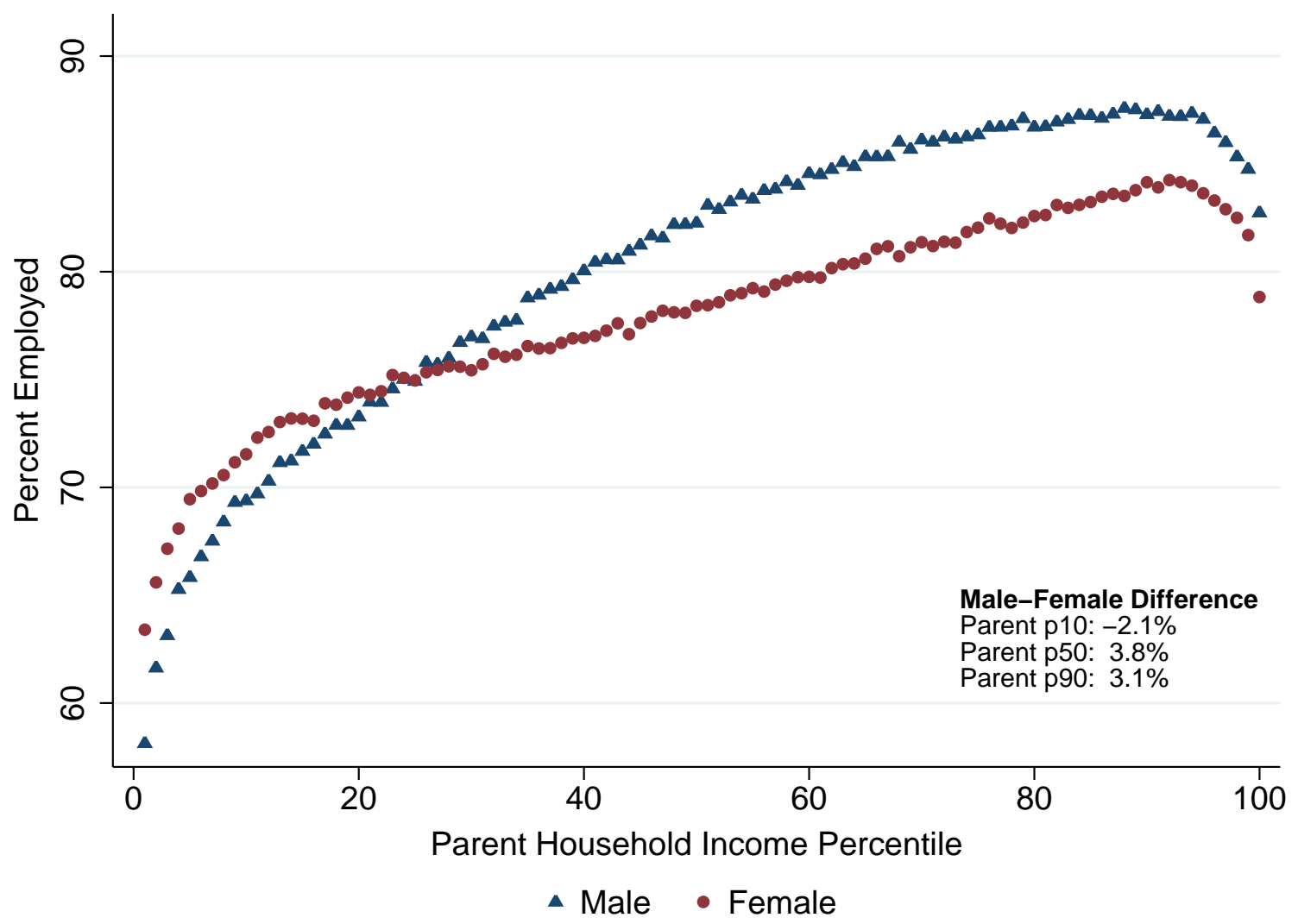

Notes: This figure plots children's employment rates vs. the percentile rank of their parents by children's gender. The sample consists of children in the 1980-82 birth cohorts. Child employment is defined as having positive W-2 wage earnings at age 30. Parent income is mean family income from 1996-2000. We bin parent family income into 100 equal-sized (centile) bins within each child cohort and plot the fraction of children who are employed in each bin. 
Figure 2. Children's Employment Rates by Gender and Parent Income Quintile: New York vs. Charlotte CZs

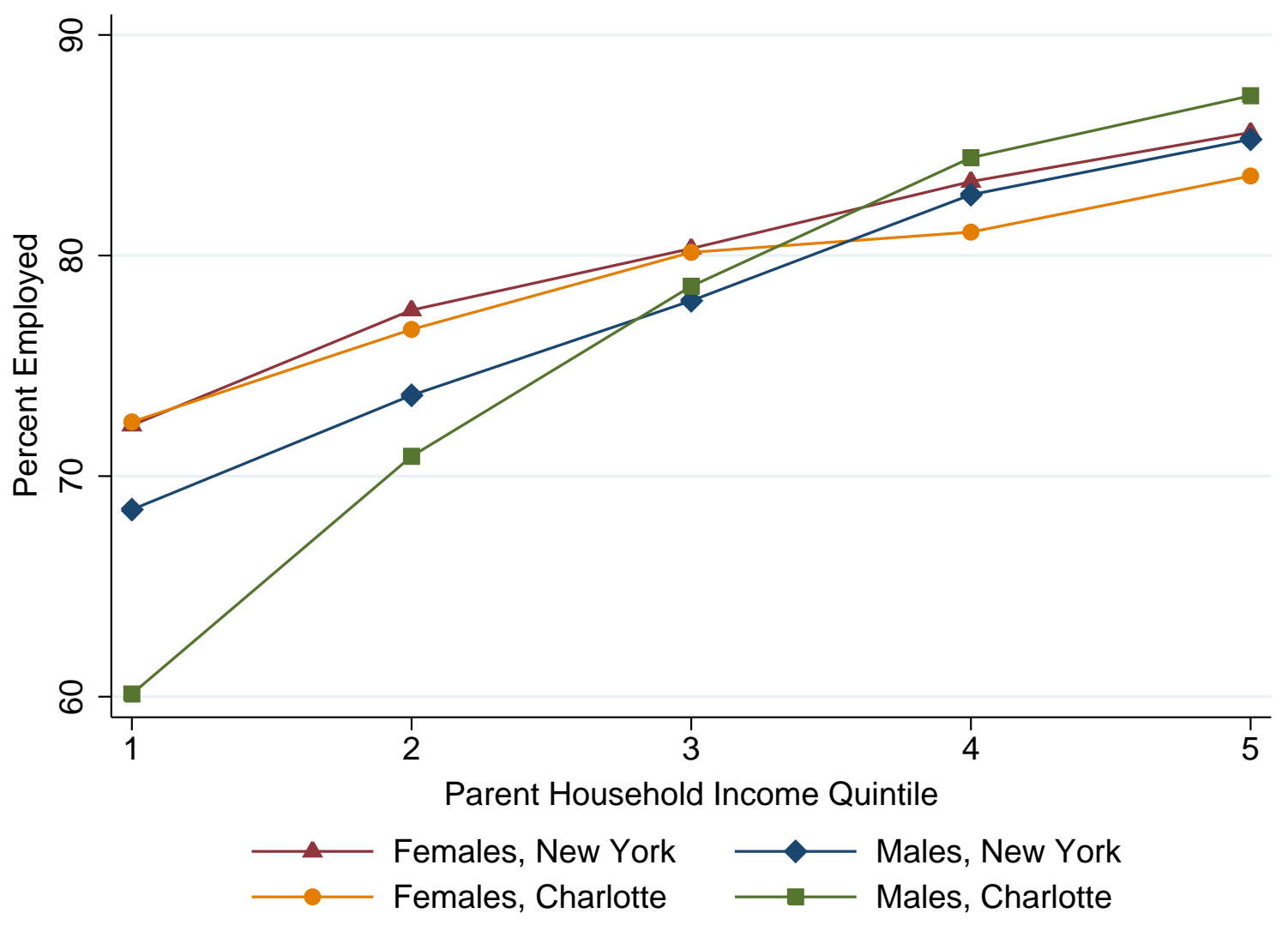

Notes: This figure plots children's employment rates by gender and parent income quintile for children who grew up in the Charlotte and New York City commuting zones (CZs). The sample consists of children in the 1980-82 birth cohorts whose parents stayed in the same CZ (Charlotte or New York) throughout our sample window, 1996-2012. Child employment is defined as having positive W-2 wage earnings at age 30. Parents are grouped into quintiles based on their ranks in the national income distribution relative to other parents with children in the same birth cohort. 
Figure 3. Gender Differences in Employment Rates by CZ for Children with Parents in Bottom Income Quintile

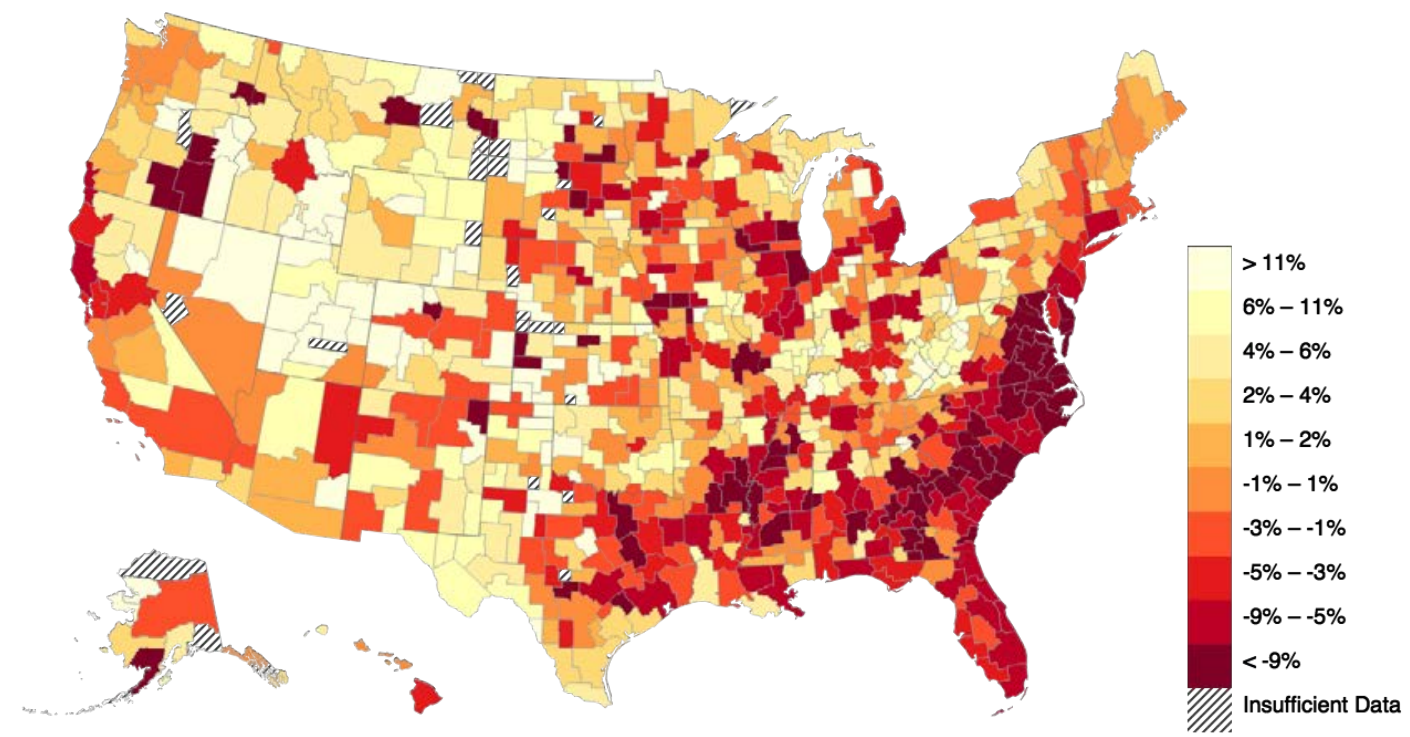

Notes: This map shows the difference in employment rates at age 30 (males - females) by the CZ where children grew up (i.e., the CZ where their parents lived). The sample consists of children in the 1980-82 birth cohorts whose parents stay in the same CZ throughout our sample window, 1996-2012, and who are in the bottom quintile of the national income distribution. Darker colors represent areas where men have lower employment rates than women. 


\section{Figure 4. Correlates of Gender Differences in Employment Rates Across CZs}

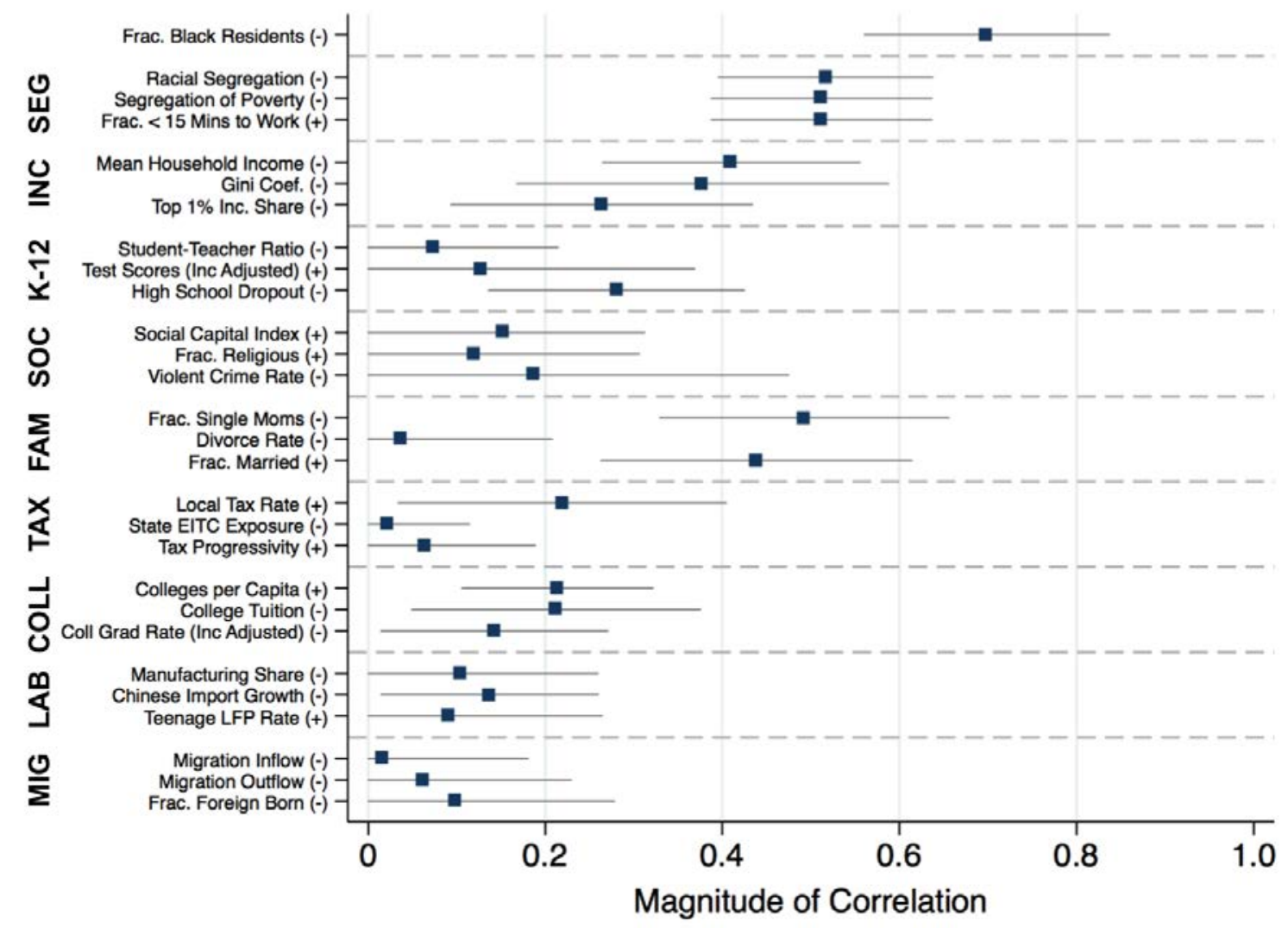

Notes: This figure presents correlations of the gender differences in employment rates (males - females) for children with parents in the bottom income quintile with a set of CZ-level characteristics constructed in Chetty et al. (2014). We consider nine categories of covariates: race and segregation, properties of the income distribution, K-12 education, social capital, family structure, local tax policies, college education, labor market conditions, and migration rates. See Appendix G of Chetty et al. (2014) for definitions and sources of each variable. For each characteristic listed on the y axis, the dot shows the absolute value of the univariate correlation between the $\mathrm{CZ}$ characteristic and the gender difference in employment rates (males - females) for children who grew up in that CZ. The horizontal bars show $95 \%$ confidence intervals based on standard errors clustered by state. Positive correlations are shown by $(+)$ on the y axis; negative correlations are shown by (-). All correlations are population weighted using CZ populations in the 2000 Census. 


\section{Appendix Figure 1. Employment Rates by Gender and Parent Income: Robustness Checks}

\section{A. W-2 + 1099 Non-Employee Income}

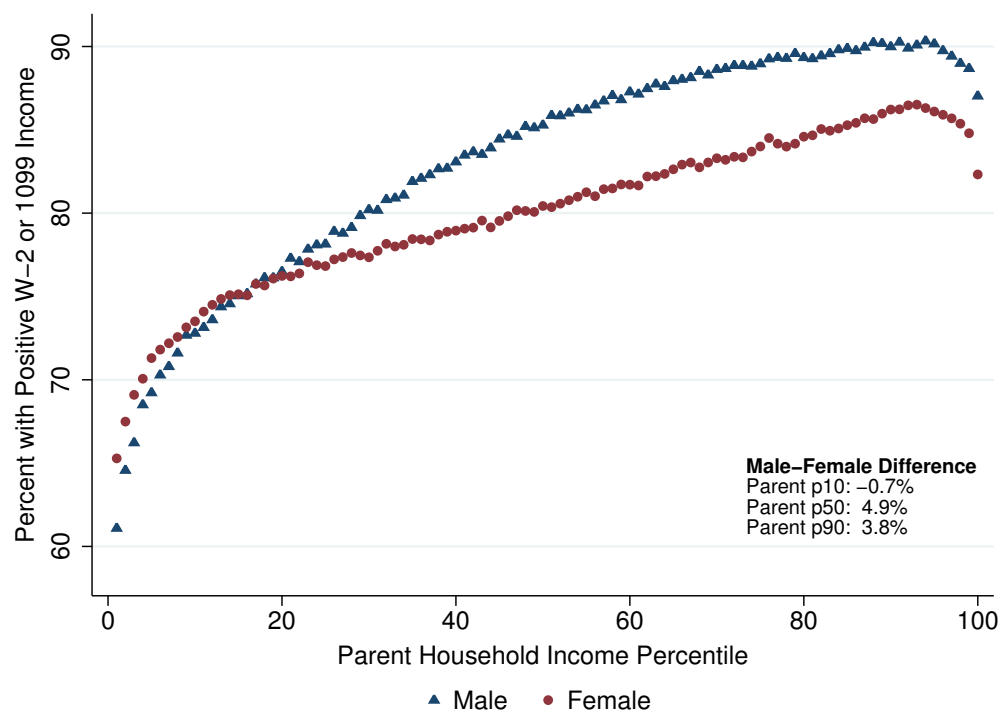

B. W-2 + Schedule C Income

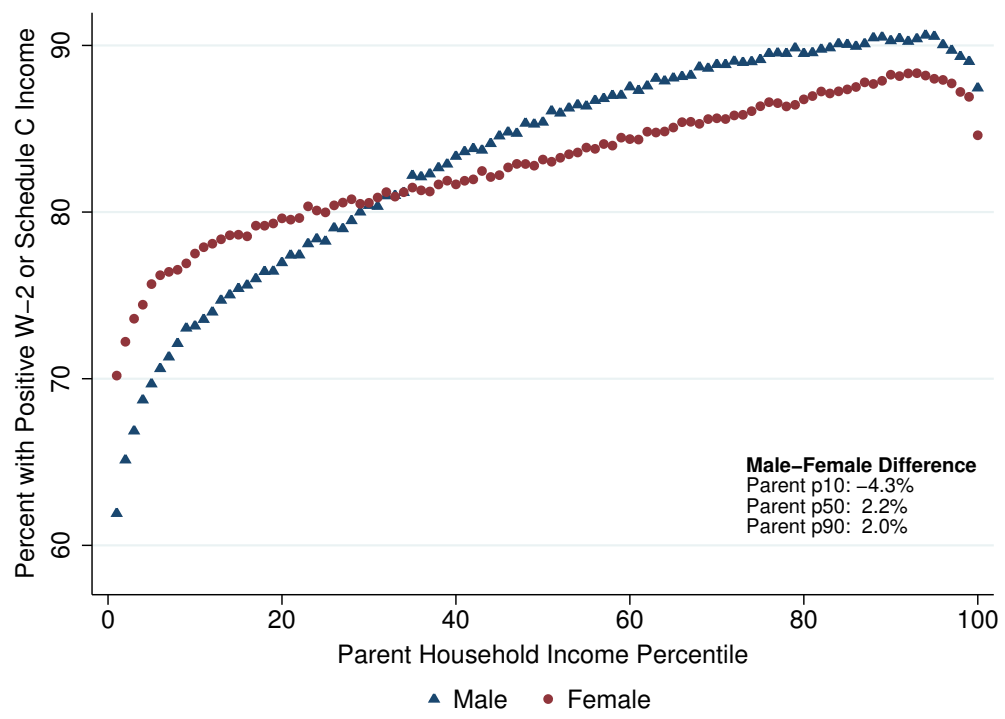

Notes: These figures replicate Figure 1 using alternative measures of employment. Panel A replicates Figure 1 defining employment as an indicator for having either a W-2 form or non-zero non-employee compensation in Form 1099 (box 7 ) in the tax year during which the child turns 30 years old. Non-employee compensation includes payments to independent contractors as well as other forms of income that may not be from employment, such as prize winnings. Panel B replicates Figure 1 defining employment as an indicator for having either a W-2 form or non-zero Schedule C income in the tax year during which the child turns 30 years old. The Schedule C form includes self-employment income, but only one form is filed for married spouses filing jointly. As a result, unemployed individuals whose spouses have self-employment income would be counted as employed in Panel B. 


\section{Appendix Figure 2. Employment Rates by Gender and Parent Income in the Panel Study of Income Dynamics}

A. All Children Born after Jan 1, 1970

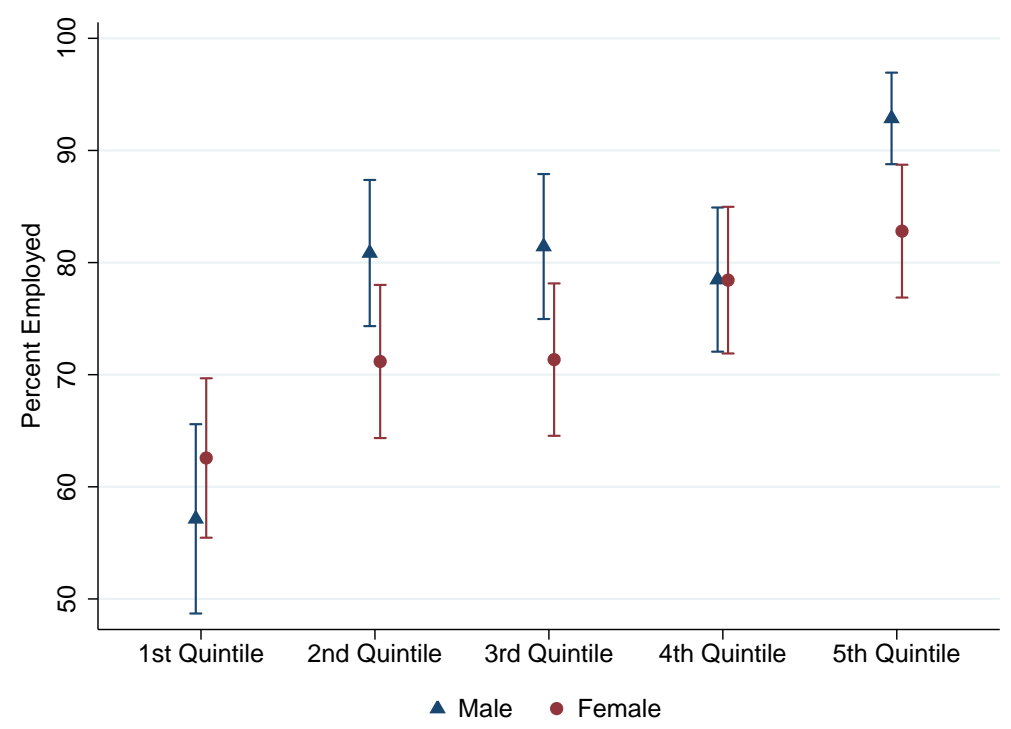

B. Trends in Male and Female Employment for Children with Parents in Bottom Income Quintile, 1950-1984

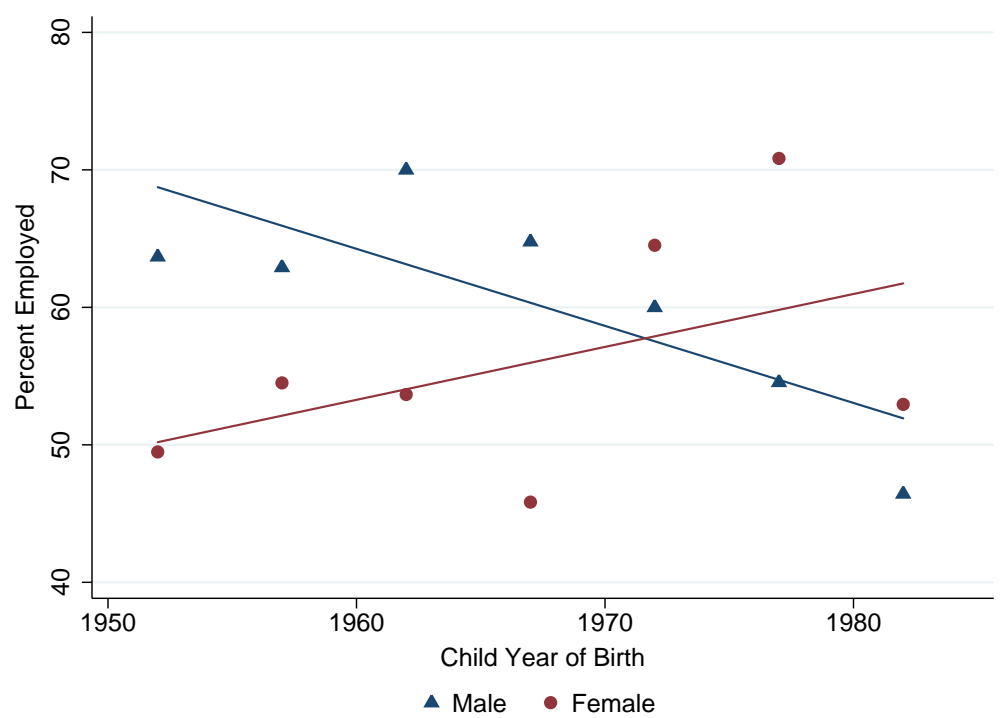

Notes: This figure shows employment patterns for children in the PSID by gender and parental income. The sample consists of all children in the PSID observed at age 30 who have non-missing parental income measures. We define employment as being currently employed or temporarily laid off (see Appendix A for details). We define parental income as mean labor income averaged over all years when the parents are between the ages 30 and 50 for which we observe them in the sample. Panel A pools all cohorts from 1970-1984 and reports employment rates by parental income quintile (defining quintiles within each birth cohort) for males and females at age 30, along with 95\% confidence intervals for these estimates. Panel B reports estimates of employment rates for men and women with parents in the bottom income quintile by birth cohort (in five-year bins), along with linear trend estimates. 


\section{Appendix Figure 3. Employment Rates by Gender and Parent Income: Single vs. Married Parents}

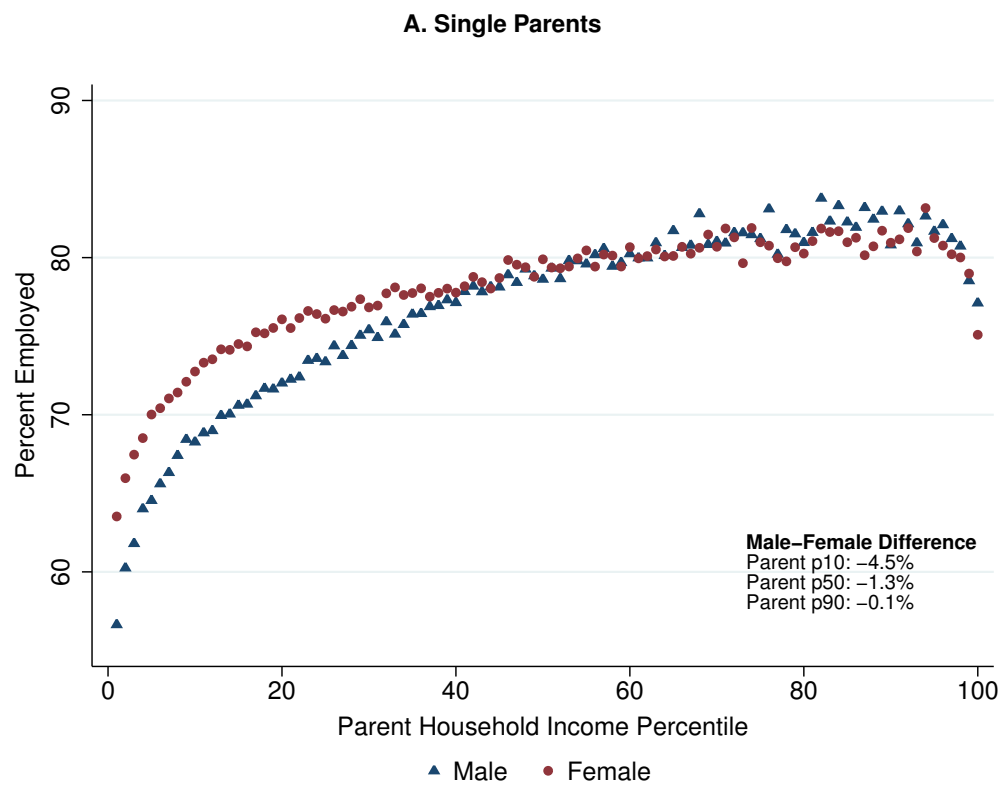

B. Married Parents

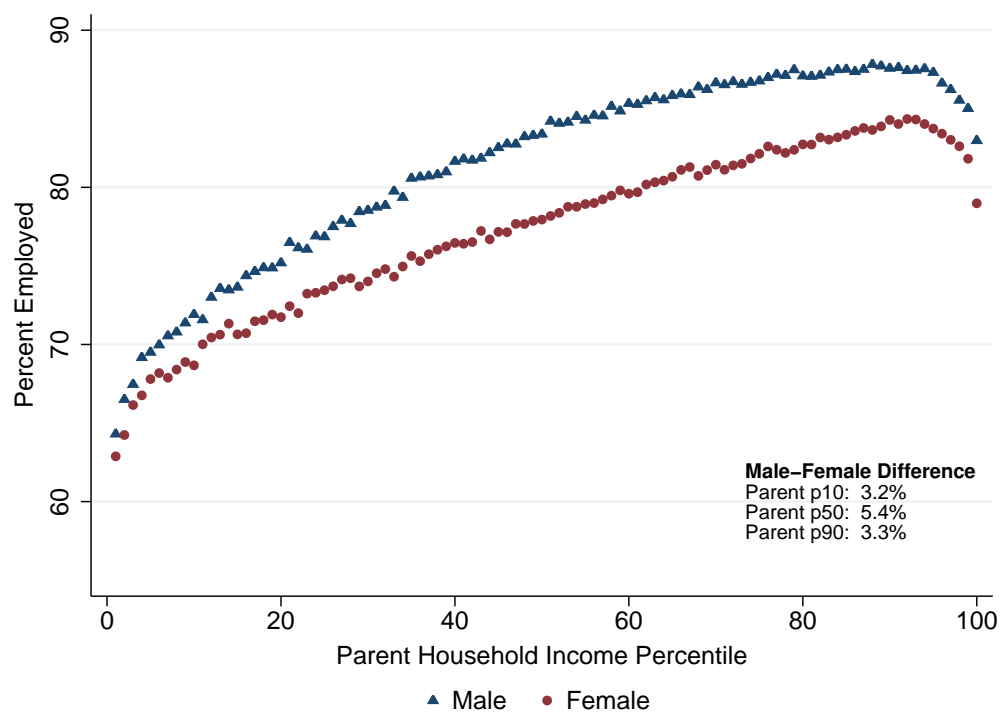

Notes: This figure replicates Figure 1, splitting the sample into children with single (Panel A) and married (Panel B) parents. Parent income ranks are the same as those used in Figure 1, pooling across married and un-married parents. Parental marital status is defined as the parents' marital status on the tax form on which the child is first claimed as a dependent. 


\section{Appendix Figure 4. Other Outcomes by Gender and Parent Income Percentile}
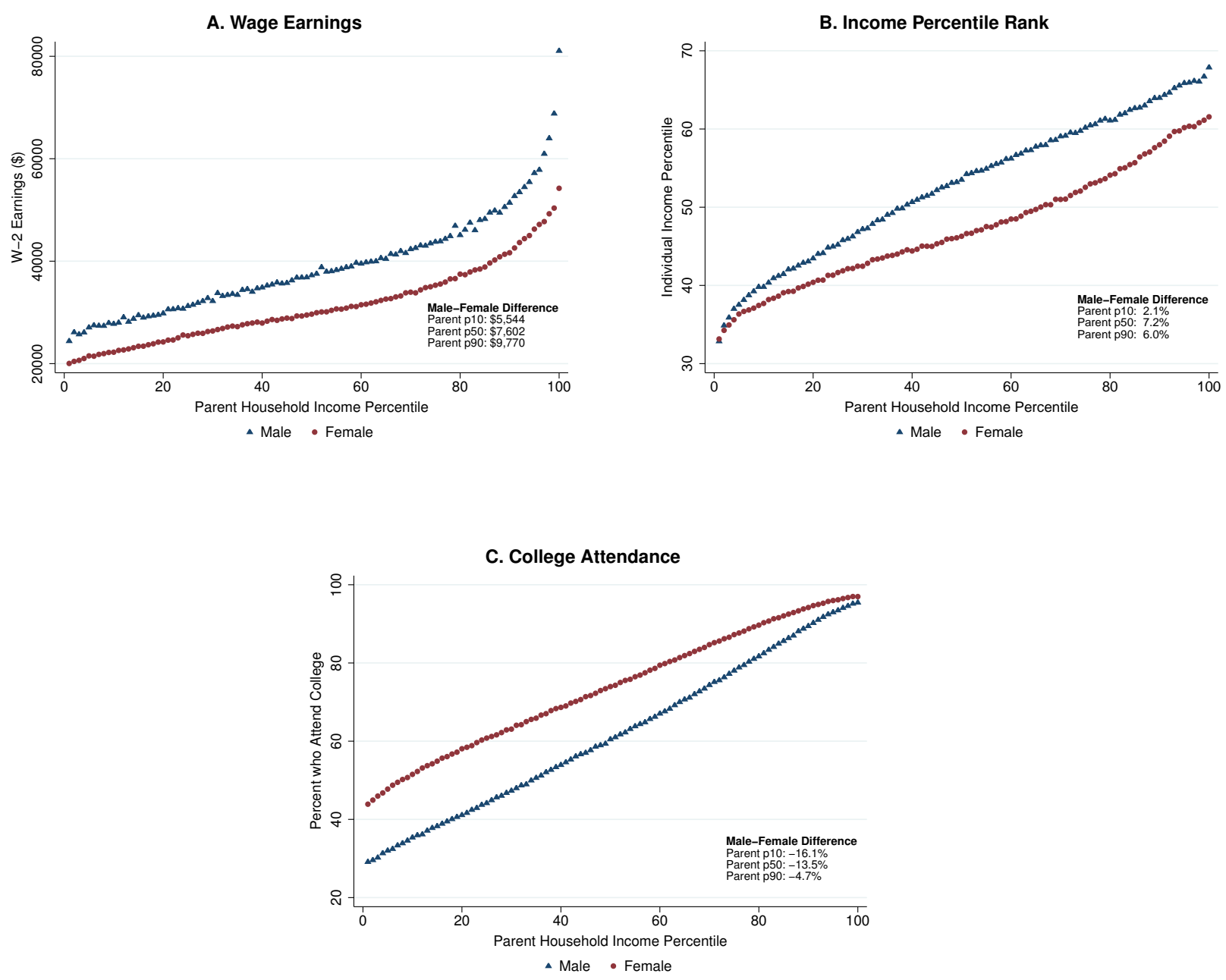

Notes: These figures replicate Figure 1 using three different outcomes for children: wage earnings (Panel A), individual income rank (Panel B), and college attendance rates (Panel C). Wage earnings is defined as the sum of all earnings on W-2s in the tax year during which the child turns age 30. Following Chetty et al. (2014), individual income is defined as the sum of wage earnings, unemployment income, disability income, and other (e.g. self employment) income from Schedule C (selfemployment income is divided by 2 for married spouses). We translate this income measure into percentile ranks by ranking children relative to other children in the same birth cohort. College attendance is defined as an indicator for having a 1098- $\mathrm{T}$ form filed by a higher education institution on one's behalf between ages 18-23. Panels A and B use the 1980-82 birth cohorts, for whom we observe outcomes at age 30 in our dataset (which ends in 2012). Panel C uses the 1981-89 birth cohorts, for whom we observe outcomes at ages 18-23. 


\section{Appendix Figure 5. Gender Differences in Employment Rates by County for Children with Parents in Bottom Income Quintile}

A. Baltimore

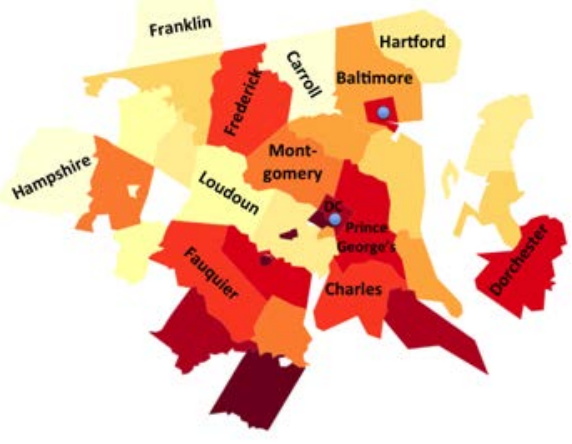

C. New York

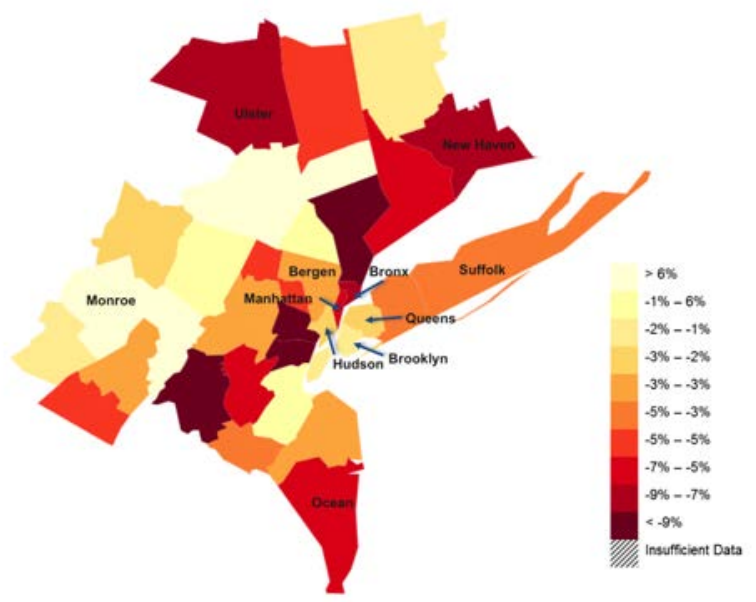

B. Chicago

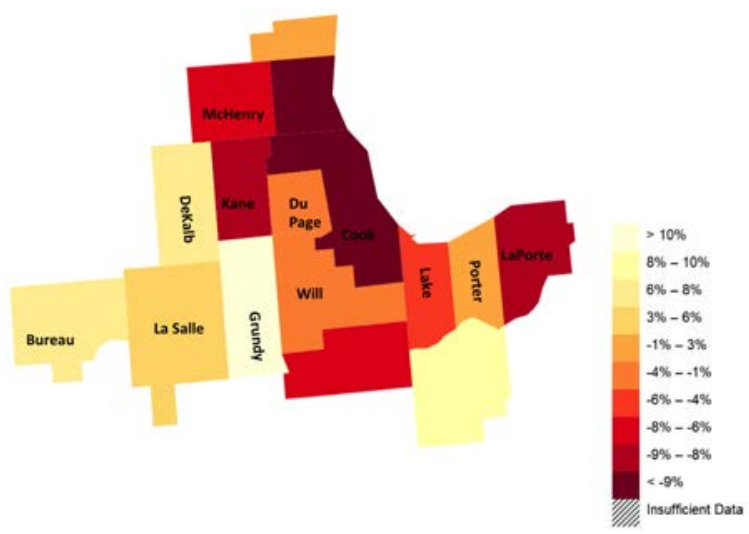

D. Detroit

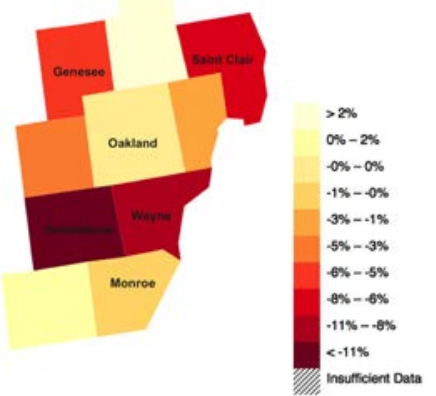

Notes: These maps show the difference in employment rates at age 30 (males - females) by the county where children grew up (i.e., the county where their parents lived). The sample consists of children in the 1980-82 birth cohorts whose parents stay in the same county throughout our sample window, 1996-2012, and who are in the bottom quintile of the national income distribution. Darker colors represent areas where men have lower employment rates than women. We show maps for counties in four combined statistical areas (CSAs): Baltimore, Chicago, New York, and Detroit. 


\section{Appendix Figure 6. Standard Deviations of Employment Rates Across CZs by Gender and Parent Income Quintile}

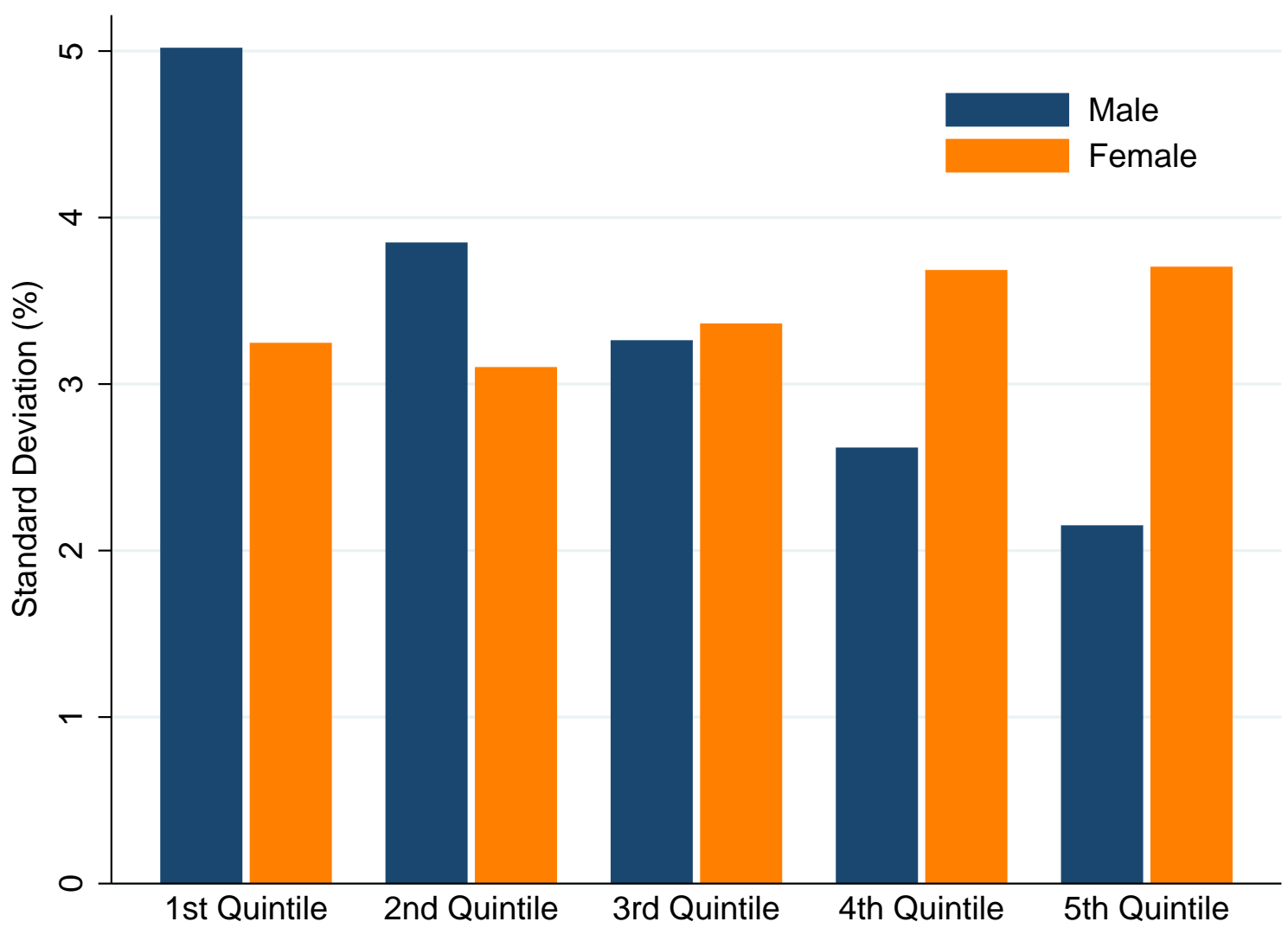

Notes: This figure plots the standard deviation of employment rates across CZs for men and women by parent income quintile. The sample consists of children in the 1980-82 birth cohorts whose parents stay in the same CZ throughout our sample window, 1996-2012. Parents are grouped into quintiles based on their ranks in the national income distribution relative to other parents with children in the same birth cohort. Each value plotted in the figure is constructed in three steps. First, we compute the total variance of the employment rates across $\mathrm{CZs}$ for each gender and parent income quintile, weighting by the population of the CZ in the 2000 Census. Second, we calculate the portion of this variance that is due to estimation error (the noise variance) by squaring the standard errors of the employment rate estimates in each CZ and taking the (population-weighted) mean of these values. Finally, we subtract the noise variance from the total variance of employment rates across $\mathrm{CZs}$ to obtain estimates of the signal variance. The figure plots the square root of these values (the signal standard deviations) in each group. 


\section{Appendix Figure 7. Standard Deviations of Employment Rates Across CZs by Gender and Parent Income Quintile: Single vs. Married Parents}

A. Single Parents

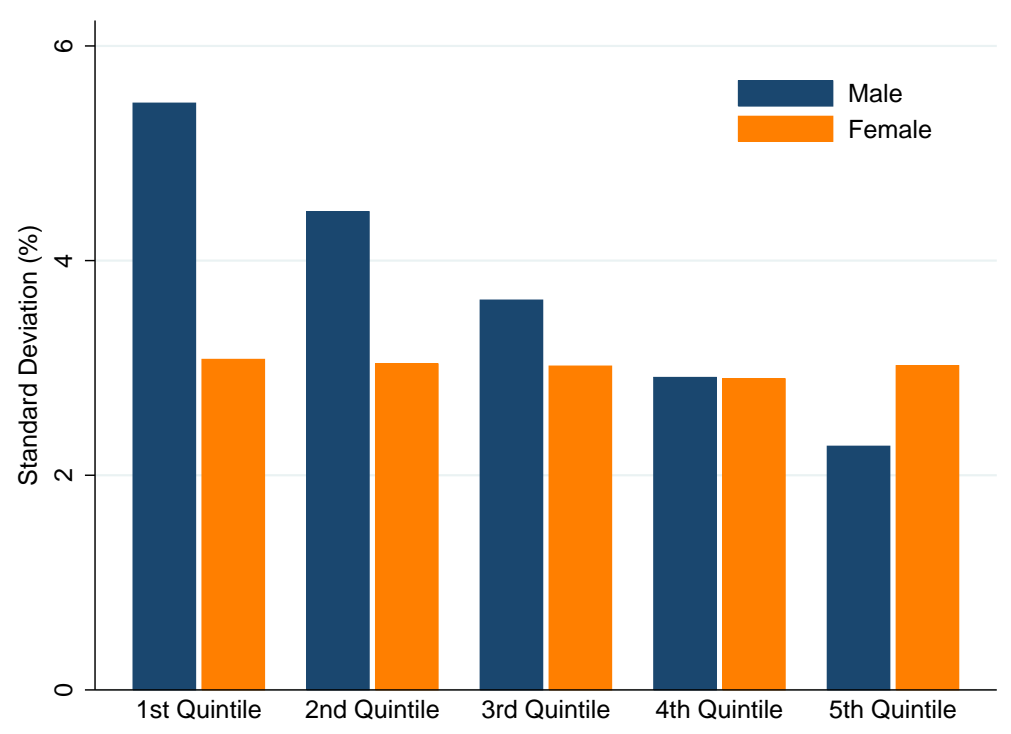

B. Married Parents

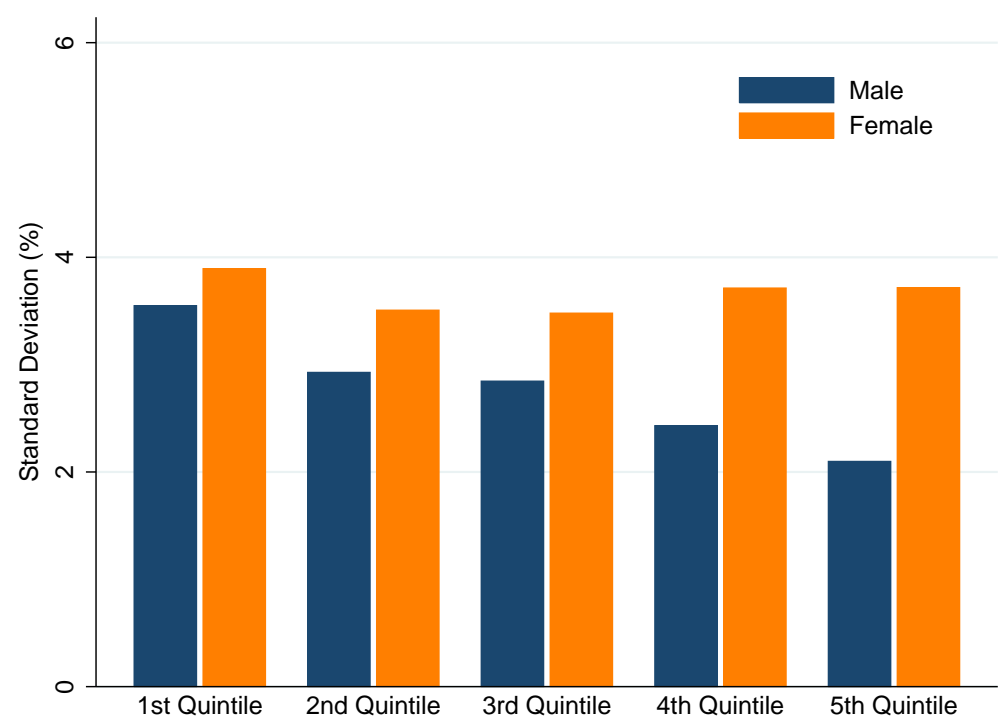

Notes: This figure replicates Appendix Figure 6, splitting the sample into children with single (Panel A) and married (Panel B) parents. Parent income ranks are the same as those used in Appendix Figure 6, pooling across married and un-married parents. Parental marital status is defined as the parents' marital status on the tax form on which the child is first claimed as a dependent. 


\section{APPENDIX TABLE 1}

Gender Differences in Employment Rates for Children with Parents in the Bottom Quintile: Top and Bottom $10 \mathrm{CZs}$

\begin{tabular}{|c|c|c|c|c|c|c|c|c|c|}
\hline Rank & $\mathrm{CZ}$ & $\begin{array}{c}\text { Difference } \\
\text { (1) }\end{array}$ & $\begin{array}{c}\text { Male } \\
(2)\end{array}$ & $\begin{array}{c}\text { Female } \\
(3)\end{array}$ & Rank & $\mathrm{CZ}$ & $\begin{array}{c}\text { Difference } \\
\text { (1) }\end{array}$ & $\begin{array}{c}\text { Male } \\
(2)\end{array}$ & $\begin{array}{c}\text { Female } \\
(3)\end{array}$ \\
\hline 1 & Salt Lake City, UT & 9.8 & 78.9 & 69.1 & 91 & Milwaukee, WI & -9.2 & 65.0 & 74.2 \\
\hline 2 & Bakersfield, CA & 7.3 & 76.8 & 69.5 & 92 & Dallas, TX & -9.4 & 64.7 & 74.1 \\
\hline 3 & El Paso, TX & 7.2 & 81.8 & 74.6 & 93 & Washington DC, DC & -9.7 & 66.6 & 76.3 \\
\hline 4 & Brownsville, TX & 5.8 & 82.6 & 76.8 & 94 & St. Louis, MO & -11.0 & 65.0 & 76.0 \\
\hline 5 & Erie, PA & 4.1 & 75.6 & 71.5 & 95 & Atlanta, GA & -11.1 & 59.3 & 70.4 \\
\hline 6 & Eugene, OR & 4.0 & 69.0 & 65.0 & 96 & Virginia Beach, VA & -11.6 & 65.0 & 76.6 \\
\hline 7 & Canton, $\mathrm{OH}$ & 3.7 & 69.0 & 65.3 & 97 & Charlotte, NC & -12.4 & 60.1 & 72.5 \\
\hline 8 & Reading, PA & 3.2 & 73.7 & 70.5 & 98 & Raleigh, NC & -13.6 & 59.9 & 73.5 \\
\hline 9 & Spokane, WA & 2.5 & 70.3 & 67.8 & 99 & Memphis, TN & -15.3 & 59.2 & 74.5 \\
\hline 10 & Syracuse, NY & 2.4 & 74.2 & 71.8 & 100 & Richmond, VA & -16.0 & 62.3 & 78.3 \\
\hline
\end{tabular}

Notes: This table presents the male-female difference in employment rates as well as the levels of male and female employment rates for selected CZs in which children grew up. The commuting zones displayed are the top ten and bottom ten commuting zones by male-female employment rate difference, among the 100 most populous commuting zones in the U.S. The sample consists of children in the 1980-82 birth cohorts whose parents stay in the same CZ throughout our sample window, 1996-2012, and who are in the bottom quintile of the national income distribution. 
APPENDIX TABLE 2

Correlations between Gender Differences in Employment Rates for Children with Parents in Bottom Income Quintile and CZ Characteristics

\begin{tabular}{|c|c|c|c|c|c|c|c|c|c|c|}
\hline & & \multicolumn{6}{|c|}{ Regression Coefficients } & \multicolumn{3}{|c|}{ Correlations } \\
\hline & & \multicolumn{2}{|c|}{$\begin{array}{c}\text { Full Sample } \\
\text { (1) }\end{array}$} & \multicolumn{2}{|c|}{$\begin{array}{c}\text { Married Parents } \\
\text { (2) }\end{array}$} & \multicolumn{2}{|c|}{$\begin{array}{c}\text { Single Parents } \\
\text { (3) }\end{array}$} & \multirow{2}{*}{$\begin{array}{c}\text { Full Sample } \\
\text { (4) } \\
\text { Corr }\end{array}$} & \multirow{2}{*}{$\begin{array}{c}\text { Married } \\
\text { Parents } \\
(5) \\
\text { Corr } \\
\end{array}$} & \multirow{2}{*}{$\begin{array}{c}\text { Single } \\
\text { Parents } \\
(6) \\
\text { Corr } \\
\end{array}$} \\
\hline & & Coeff & (s.e.) & Coeff & (s.e.) & Coeff & (s.e.) & & & \\
\hline \multirow{4}{*}{$\begin{array}{l}\text { Segregation } \\
\text { and Poverty }\end{array}$} & Fraction Black Residents & -3.848 & $(0.388)$ & -1.884 & $(0.373)$ & -4.102 & $(0.404)$ & -0.699 & -0.368 & -0.700 \\
\hline & Racial Segregation & -2.845 & $(0.340)$ & -1.364 & $(0.357)$ & -3.068 & $(0.304)$ & -0.517 & -0.267 & -0.524 \\
\hline & Segregation of Poverty & -2.820 & $(0.350)$ & -1.759 & $(0.325)$ & -2.933 & $(0.336)$ & -0.512 & -0.344 & -0.501 \\
\hline & Fraction $<15$ Mins to Work & 2.820 & $(0.349)$ & 1.709 & $(0.302)$ & 2.982 & $(0.328)$ & 0.512 & 0.334 & 0.509 \\
\hline \multirow{3}{*}{$\begin{array}{c}\text { Income } \\
\text { Distribution }\end{array}$} & Mean Household Income & -2.259 & $(0.408)$ & -1.752 & $(0.273)$ & -2.233 & $(0.441)$ & -0.410 & -0.343 & -0.381 \\
\hline & Gini Coefficient (Bottom 99\%) & -2.081 & $(0.590)$ & -1.403 & $(0.521)$ & -2.220 & $(0.540)$ & -0.378 & -0.274 & -0.379 \\
\hline & Top 1\% Income Share & -1.452 & $(0.478)$ & -1.200 & $(0.522)$ & -1.513 & $(0.434)$ & -0.264 & -0.235 & -0.258 \\
\hline \multirow{3}{*}{$\begin{array}{c}\mathrm{K}-12 \\
\text { Education }\end{array}$} & Student-Teacher Ratio & 0.405 & $(0.395)$ & 0.035 & $(0.470)$ & 0.441 & $(0.452)$ & 0.073 & 0.007 & 0.076 \\
\hline & Test Scores (Income Adjusted) & 0.696 & $(0.681)$ & 0.748 & $(0.251)$ & 0.578 & $(0.770)$ & 0.126 & 0.146 & 0.099 \\
\hline & High School Dropout Rate (Income Adjusted) & -1.606 & $(0.421)$ & -0.519 & $(0.326)$ & -1.697 & $(0.432)$ & -0.281 & -0.097 & -0.276 \\
\hline \multirow{3}{*}{$\begin{array}{l}\text { Social } \\
\text { Capital }\end{array}$} & Social Capital Index (Rupasingha and Goetz 2008) & 0.843 & $(0.447)$ & 0.413 & $(0.300)$ & 0.977 & $(0.510)$ & 0.153 & 0.081 & 0.167 \\
\hline & Fraction Religious & 0.657 & $(0.525)$ & 0.453 & $(0.451)$ & 0.634 & $(0.551)$ & 0.119 & 0.089 & 0.108 \\
\hline & Violent Crime Rate & -1.049 & $(0.818)$ & -0.793 & $(0.436)$ & -1.157 & $(0.945)$ & -0.188 & -0.153 & -0.195 \\
\hline \multirow{3}{*}{$\begin{array}{l}\text { Family } \\
\text { Structure }\end{array}$} & Fraction of Children with Single Mothers & -2.714 & $(0.458)$ & -1.317 & $(0.506)$ & -2.932 & $(0.388)$ & -0.493 & -0.258 & -0.501 \\
\hline & Fraction of Adults Divorced & 0.204 & $(0.479)$ & 0.374 & $(0.396)$ & 0.216 & $(0.521)$ & 0.037 & 0.073 & 0.037 \\
\hline & Fraction of Adults Married & 2.415 & $(0.493)$ & 1.620 & $(0.461)$ & 2.503 & $(0.449)$ & 0.439 & 0.317 & 0.427 \\
\hline \multirow{3}{*}{ Tax } & Local Tax Rate & -1.208 & $(0.521)$ & -0.823 & $(0.467)$ & -1.313 & $(0.480)$ & -0.219 & -0.161 & -0.224 \\
\hline & State EITC Exposure & 0.117 & $(0.261)$ & -0.240 & $(0.288)$ & 0.260 & $(0.304)$ & 0.021 & -0.047 & 0.044 \\
\hline & Tax Progressivity & 0.356 & $(0.348)$ & -0.524 & $(0.215)$ & 0.599 & $(0.366)$ & 0.065 & -0.103 & 0.102 \\
\hline \multirow{3}{*}{ College } & Number of Colleges per Capita & 1.157 & $(0.297)$ & 0.817 & $(0.230)$ & 1.190 & $(0.325)$ & 0.214 & 0.163 & 0.207 \\
\hline & Mean College Tuition & -1.148 & $(0.449)$ & -0.768 & $(0.337)$ & -1.237 & $(0.474)$ & -0.212 & -0.153 & -0.215 \\
\hline & College Graduation Rate (Income Adjusted) & 0.770 & $(0.353)$ & 0.400 & $(0.292)$ & 0.734 & $(0.373)$ & 0.142 & 0.080 & 0.128 \\
\hline \multirow{3}{*}{$\begin{array}{l}\text { Local Labor } \\
\text { Market }\end{array}$} & Fraction Working in Manufacturing & 0.576 & $(0.434)$ & 0.590 & $(0.369)$ & 0.578 & $(0.454)$ & 0.105 & 0.115 & 0.099 \\
\hline & Growth in Chinese Imports 1990-2000 (Autor and Dorn 2013) & 0.755 & $(0.344)$ & 0.075 & $(0.306)$ & 1.061 & $(0.361)$ & 0.137 & 0.015 & 0.181 \\
\hline & Teenage (14-16) LFP Rate & 0.502 & $(0.486)$ & 0.220 & $(0.310)$ & 0.630 & $(0.564)$ & 0.091 & 0.043 & 0.108 \\
\hline \multirow{3}{*}{ Migration } & Migration Inflow Rate & -0.091 & $(0.461)$ & -0.095 & $(0.356)$ & -0.061 & $(0.521)$ & -0.017 & -0.019 & -0.010 \\
\hline & Migration Outflow Rate & -0.341 & $(0.470)$ & -0.534 & $(0.345)$ & -0.281 & $(0.502)$ & -0.062 & -0.104 & -0.048 \\
\hline & Fraction of Foreign Born Residents & -0.539 & $(0.505)$ & -0.907 & $(0.300)$ & -0.493 & $(0.592)$ & -0.098 & -0.177 & -0.084 \\
\hline
\end{tabular}

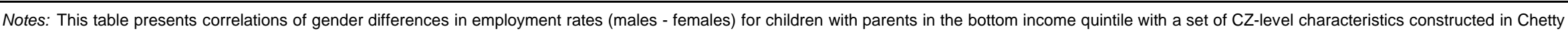

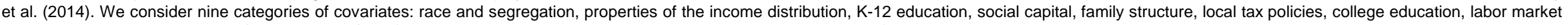

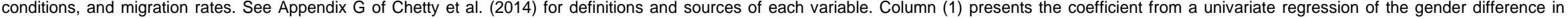

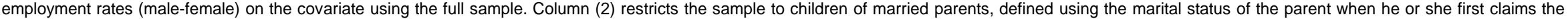

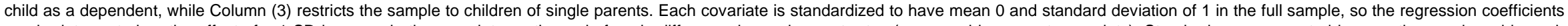
can be interpreted as the effect of a 1 SD increase in the covariate on the male-female difference in employment rates (measured in percentage points). Standard errors, reported in parentheses alongside each

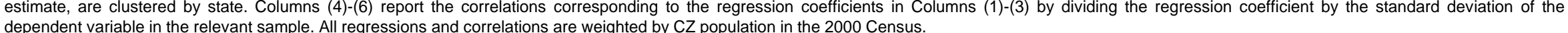




\section{APPENDIX TABLE 3}

Correlates of Gender Gaps in Permanent Residents' Outcomes vs. Causal Effects based on Movers

\begin{tabular}{lccccc}
\hline \hline & \multicolumn{5}{c}{ Panel A: Male-Female Difference in Employment Rates } \\
\cline { 2 - 5 } & $(1)$ & $(2)$ & $(3)$ & $(4)$ & $(5)$ \\
\hline \multirow{2}{*}{ Segregation of Poverty } & -2.823 & & & -1.620 & -1.948 \\
& $(0.350)$ & & & $(0.323)$ & $(0.197)$ \\
\% Black & & -3.848 & -3.552 & -3.335 \\
& & $(0.388)$ & & $(0.536)$ & $(0.563)$ \\
\% Single Mothers & & -2.716 & 0.404 & 0.526 & $(0.413)$ \\
State FE & & & $(0.459)$ & $(0.666)$ & $X$
\end{tabular}

Panel B: Male-Female Difference in Mean Income Rank

$(1) \quad(2) \quad(3) \quad(4) \quad(5)$

\begin{tabular}{|c|c|c|c|c|c|}
\hline Segregation of Poverty & $\begin{array}{l}-3.030 \\
(0.231)\end{array}$ & & & $\begin{array}{l}-2.485 \\
(0.246)\end{array}$ & $\begin{array}{l}-2.231 \\
(0.186)\end{array}$ \\
\hline$\%$ Black & & $\begin{array}{l}-2.389 \\
(0.442)\end{array}$ & & $\begin{array}{l}-1.311 \\
(0.410)\end{array}$ & $\begin{array}{l}-1.820 \\
(0.449)\end{array}$ \\
\hline$\%$ Single Mothers & & & $\begin{array}{l}-1.890 \\
(0.441)\end{array}$ & $\begin{array}{l}-0.217 \\
(0.516)\end{array}$ & $\begin{array}{c}0.288 \\
(0.391)\end{array}$ \\
\hline
\end{tabular}

Panel C: Male-Female Difference in Causal Effects on Income Rank using Movers

$\begin{array}{lllll}(1) & (2) & (3) & (4)\end{array}$

\begin{tabular}{|c|c|c|c|c|c|}
\hline Segregation of Poverty & $\begin{array}{l}-2.536 \\
(0.562)\end{array}$ & & & $\begin{array}{c}-2.464 \\
(0.576)\end{array}$ & $\begin{array}{l}-2.780 \\
(0.556)\end{array}$ \\
\hline$\%$ Black & & $\begin{array}{l}-1.070 \\
(0.560)\end{array}$ & & $\begin{array}{c}-0.452 \\
(0.777)\end{array}$ & $\begin{array}{c}1.389 \\
(1.326)\end{array}$ \\
\hline$\%$ Single Mothers & & & $\begin{array}{l}-0.647 \\
(0.485)\end{array}$ & $\begin{array}{c}0.350 \\
(0.743)\end{array}$ & $\begin{array}{l}-0.300 \\
(0.866)\end{array}$ \\
\hline
\end{tabular}

Notes: This table presents further evidence on the relationship between three of the CZ-level characteristics in Appendix Table 2 (segregation of poverty, fraction black, and fraction single mothers) and gender gaps in adulthood. In Panel $A$, we regress gender differences (male - female) in employment rates at age 30 for children with parents in the bottom income quintile on these characteristics. Each covariate is standardized to have mean 0 and standard deviation of 1 in the full sample, so the regression coefficients can be interpreted as the effect of a 1 SD increase in the covariate on the male-female difference in employment rates (measured in percentage points). Columns 1-3 report estimates from univariate regressions, replicating specifications reported in Appendix Table 2. Column 4 reports estimates from a multivariable regression with three of the strongest predictors of gender differences. Column 5 replicates column 4 including state fixed effects. The sample in Panel A consists of children whose parents never moved across CZs, as in Figure 3. Panel B replicates Panel A, changing the dependent variable to the gender difference in the mean individual income rank at age 26 for children with parents at the 25th percentile of the national income distribution. Individual income is defined as the sum of wage earnings, unemployment income, disability income, and other (e.g. self employment) income from Schedule $\mathrm{C}$ (self-employment income is divided by 2 for married spouses). We translate this income measure into percentile ranks (scaled from 0 $100)$ by ranking children relative to other children in the same birth cohort. Panel $C$ replicates Panel B, replacing the dependent variable with the gender difference in the causal effects of each CZ on mean individual income rank at age 26 for children with parents at the 25th percentile. These causal effect estimates are taken from Chetty and Hendren's (2015) analysis of movers. Standard errors, reported in parentheses, are clustered by state. See Appendix B for further details on the specifications in this table. 